\title{
Effects of seismic sequences on masonry structures
}

\author{
Giovanni Rinaldin ${ }^{\mathrm{a}, *}$, Claudio Amadio ${ }^{\mathrm{b}}$

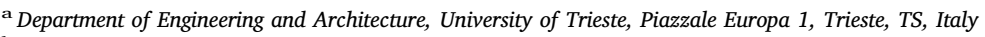 \\ ${ }^{\mathrm{b}}$ Department of Engineering and Architecture, University of Trieste, Piazzale Europa n. 1, 34127 Trieste, TS, Italy
}

\section{A R T I C L E I N F O}

\section{Keywords:}

Repeated earthquake ground motions

Hysteretic behaviour

Masonry structures

Behaviour factor

Non-linear SDOF

Damage index

\begin{abstract}
A B S T R A C T
In this work, the seismic behaviour of UnReinforced Masonry (URM) structures under repeated earthquakes is investigated. Such analysis is carried-out by using a purposely-developed non-linear software that describes the hysteretic behaviour of a masonry panel through an appropriate phenomenological law. First, results obtained from a series of non-linear dynamic analyses on a single degree of freedom (SDOF) system, which represents the typical cyclic response of an unreinforced masonry structure, are presented. The seismic sequences adopted for the analysis are taken from international databases and are selected on the base of the Peak Ground Acceleration (PGA) of the events following the mainshock. The selected aftershocks have a PGA equal or almost similar to the mainshock, in such a way to significantly influence of the required ductility for the analysed system and, consequently, on the damage index used to quantify the structural degradation.

The obtained results are presented in terms of inelastic response at constant ductility or strength. On the base of the collected results, modifications on the behaviour factors commonly adopted in seismic design are proposed. Finally, a SDOF system representing a typical masonry structure subjected to the seismic sequence of Central Italy (2016) has been analysed with the aim to highlight the damage evolution.
\end{abstract}

\section{Introduction}

The recent seismic events in Central Italy [1] evidenced the fragility of masonry buildings in the Italian historic towns, particularly under the effect of a seismic sequence having aftershocks with PGA equal or similar to the mainshock. For instance, the town centres of Amatrice and Accumuli, province of Rieti, strongly suffered a progressive collapse of unreinforced masonry (URM) structures after the events of 24th of August 2016 and 30th of October [2], as shown in Fig. 1.

The behaviour of structures subjected to repeated seismic events has been already investigated in the past. Amadio et al. [3] reported the effects of repeated earthquakes on a SDOF system; Hatzigeorgiou and Beskos used the inelastic displacement ratios for measuring the inelastic demand on SDOF systems [4].

In general, all the structures may be designed adopting the resilience concept $[3,5]$, that is the ability of a system to revert to a fully operational state after an event that interrupts its functionality or use for a while time. In structural field, such request can be satisfied through simple provisions, like structural redundancy, which increases the number of critical components (i.e. vertical members) in order to prevent extended damage to the building and/or supplying re-centring capacity.

In the field of structural resilience, several seismic events happening in a short time don't allow for rehabilitation of the structure, and therefore the collapse under subsequent earthquakes cannot be prevented. A first step in the direction of a correct design is then to take into account the degradation that can occur during the entire seismic sequence. In the Central Italy zone, for example, these design provisions should be taken into consideration for the reconstruction, with the aim to avoid the progressive collapses occurred in 2016.

A useful tool to achieve this, will go through the definition of a modified behaviour factor to be used in the seismic design of a masonry building. In this work, simple SDOF systems with non-linear behaviour, calibrated upon the cyclic response of URM structures, will be analysed with the final aim to obtain the inelastic responses in terms of constant ductility or strength under repeated earthquakes. The increase in ductility request will be evaluated under a series of seismic sequences, and consequently variations on commonly adopted behaviour factors will be provided. Actual behaviour factors for elastic design are in fact calibrated on the base of a single seismic event, represented by the design spectrum, and do not include damage due to aftershocks.

The usage of SDOF systems is appropriate to represent the cyclic shear behaviour of a whole masonry building, since the non-linear hysteretic law employed has the same overall shape of the base shear vs. top displacement curves that can be obtained from an experimental test on full-scale specimens, as previously showed in [7]. On the other

\footnotetext{
* Corresponding author

E-mail addresses: grinaldin@units.it (G. Rinaldin), amadio@units.it (C. Amadio).
} 


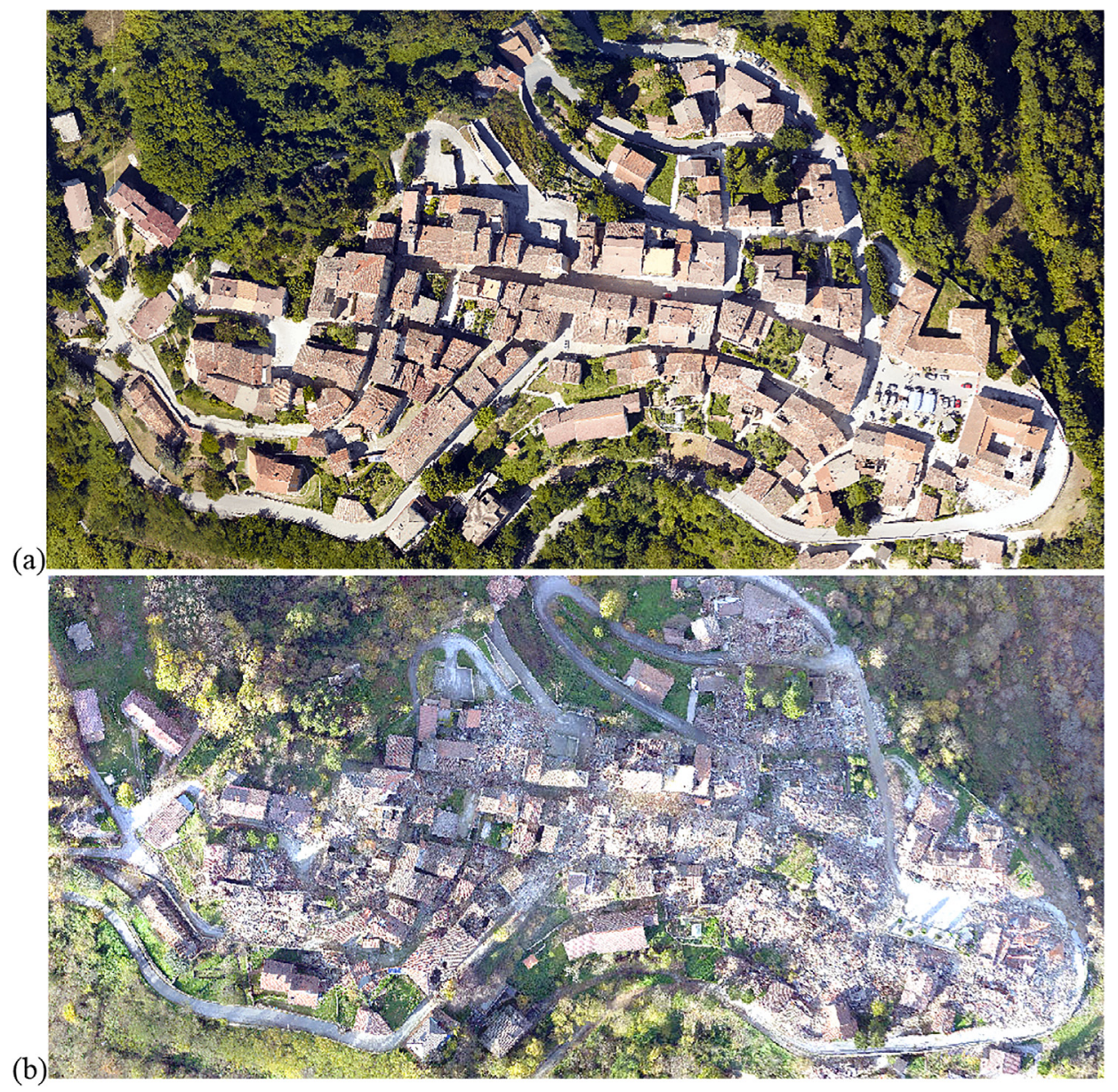

Fig. 1. Aerial view of Accumuli (province of Rieti, Central Italy) on August 24th (a) and on October 30th (b), from [6].

Table 1

List of selected seismic sequences.

\begin{tabular}{|c|c|c|c|c|c|}
\hline Sequence name & Event no. & Date & $\mathrm{Mw}$ & $\begin{array}{l}\mathrm{PGA} \\
{\left[\mathrm{m} / \mathrm{s}^{2}\right]}\end{array}$ & $\begin{array}{l}\text { Event duration } \\
\text { [s] }\end{array}$ \\
\hline \multirow{2}{*}{ Christchurch } & 1 & 03/09/2010 16:35 & 7.1 & -1.51 & 110 \\
\hline & 2 & $21 / 02 / 201123: 51$ & 6.1 & 5.56 & 110 \\
\hline \multirow[t]{3}{*}{ Nocera Umbra } & 1 & 10/06/1997 23:24 & 5.4 & -4.81 & 37 \\
\hline & 2 & 26/09/1997 00:33 & 5.7 & 4.85 & 29 \\
\hline & 3 & 26/09/1997 09:40 & 6 & -4.92 & 14 \\
\hline \multirow{3}{*}{ Mexicali Valley } & 1 & $11 / 03 / 197805: 40$ & 3.7 & 4.59 & 13 \\
\hline & 2 & $11 / 03 / 197823: 57$ & 4.8 & 4.57 & 10 \\
\hline & 3 & $12 / 03 / 197800: 30$ & 4.5 & -4.51 & 12 \\
\hline \multirow[t]{2}{*}{ Mendocino Cape } & 1 & 25/04/1992 11:06 & 7 & -5.78 & 60 \\
\hline & 2 & $26 / 04 / 199200: 41$ & 6.6 & 5.87 & 40 \\
\hline \multirow{2}{*}{ Chi Chi, Taiwan } & 1 & $20 / 09 / 1999$ 17:47 & 7.6 & -9.83 & 160 \\
\hline & 2 & 20/09/1999 18:03 & 6.2 & -9.33 & 104 \\
\hline \multirow[t]{4}{*}{ Niigata } & 1 & $23 / 10 / 2004$ 17:56 & 6.6 & -5.21 & 299 \\
\hline & 2 & $23 / 10 / 2004$ 18:34 & 6.3 & -5.26 & 299 \\
\hline & 3 & $25 / 10 / 200406: 05$ & 5.7 & -4.27 & 299 \\
\hline & 4 & $27 / 10 / 200410: 40$ & 6.0 & -5.23 & 299 \\
\hline \multirow[t]{3}{*}{ NW China } & 1 & 05/04/1997 23:46 & 5.9 & -2.29 & 45 \\
\hline & 2 & $11 / 04 / 199705: 34$ & 6.1 & 2.68 & 60 \\
\hline & 3 & 15/04/1997 18:19 & 5.8 & 2.34 & 60 \\
\hline \multirow{2}{*}{ Tohoku } & 1 & $11 / 03 / 2011$ 14:46 & 9.0 & 4.12 & 300 \\
\hline & 2 & 07/04/2011 23:32 & 7.1 & 3.89 & 184 \\
\hline \multirow[t]{2}{*}{ Hokkaido } & 1 & 29/11/2004 03:32 & 7.0 & 2.72 & 159 \\
\hline & 2 & 06/12/2004 23:15 & 6.7 & 2.93 & 121 \\
\hline \multirow[t]{2}{*}{ Weber } & 1 & 19/02/1990 05:34 & 6.2 & 1.44 & 51 \\
\hline & 2 & $13 / 05 / 199004: 23$ & 6.4 & 1.64 & 54 \\
\hline
\end{tabular}


Table 2

List of selected events for Central Italy earthquake (2016).

\begin{tabular}{|c|c|c|c|c|c|c|c|}
\hline Date & Event no. & Time & Mw & $\begin{array}{l}\text { PGA } \\
{\left[\mathrm{cm} / \mathrm{s}^{2}\right]}\end{array}$ & $\begin{array}{l}\text { Epicentral distance } \\
{[\mathrm{km}]}\end{array}$ & $\begin{array}{l}\text { Depth } \\
{[\mathrm{km}]}\end{array}$ & $\begin{array}{l}\text { Duration } \\
\text { [s] }\end{array}$ \\
\hline $24 / 08 / 2016$ & 1 & $01: 36$ & 6.0 & 352.57 & 15.3 & 8.1 & 40.0 \\
\hline $24 / 08 / 2016$ & 2 & $02: 33$ & 5.4 & 167.01 & 4.7 & 8.7 & 47.1 \\
\hline $24 / 08 / 2016$ & 3 & $02: 59$ & 4.1 & 51.50 & 3.8 & 9.0 & 44.0 \\
\hline $24 / 08 / 2016$ & 4 & 04:06 & 4.3 & 64.06 & 3.5 & 7.6 & 38.3 \\
\hline $24 / 08 / 2016$ & 5 & $17: 46$ & 4.4 & 12.00 & 17.7 & 10.0 & 42.6 \\
\hline $25 / 08 / 2016$ & 6 & $12: 36$ & 4.3 & 3.85 & 27.0 & 10.0 & 55.4 \\
\hline $26 / 08 / 2016$ & 7 & $04: 28$ & 4.8 & 6.67 & 26.6 & 10.9 & 71.7 \\
\hline $27 / 08 / 2016$ & 8 & $02: 50$ & 4.0 & 4.68 & 13.5 & 8.2 & 53.5 \\
\hline $28 / 08 / 2016$ & 9 & $15: 55$ & 4.4 & 12.83 & 12.0 & 8.7 & 72.7 \\
\hline $31 / 08 / 2016$ & 10 & $18: 12$ & 4.1 & 5.88 & 14.0 & 9.0 & 50.6 \\
\hline 03/09/2016 & 11 & $01: 34$ & 4.3 & 123.42 & 3.3 & 10.6 & 69.2 \\
\hline 03/09/2016 & 12 & $10: 18$ & 4.5 & 16.31 & 12.7 & 9.0 & 69.6 \\
\hline $15 / 09 / 2016$ & 13 & $14: 40$ & 4.3 & 10.64 & 8.2 & 10.0 & 9.7 \\
\hline $19 / 09 / 2016$ & 14 & $23: 34$ & 4.1 & 2.56 & 20.2 & 9.7 & 53.6 \\
\hline $16 / 10 / 2016$ & 15 & 09:32 & 4.1 & 16.79 & 8.3 & 9.0 & 45.1 \\
\hline $26 / 10 / 2016$ & 16 & $17: 10$ & 5.4 & 294.74 & 10.1 & 8.7 & 52.9 \\
\hline $26 / 10 / 2016$ & 17 & $19: 18$ & 5.9 & 248.28 & 13.2 & 7.5 & 57.7 \\
\hline $26 / 10 / 2016$ & 18 & $21: 42$ & 4.6 & 59.33 & 8.1 & 9.5 & 73.6 \\
\hline $27 / 10 / 2016$ & 19 & 03:19 & 4.1 & 24.46 & 7.2 & 9.0 & 57.6 \\
\hline $27 / 10 / 2016$ & 20 & $03: 50$ & 4.4 & 7.12 & 21.7 & 8.9 & 58.3 \\
\hline $27 / 10 / 2016$ & 21 & $08: 21$ & 4.4 & 27.13 & 9.0 & 9.3 & 43.8 \\
\hline $30 / 10 / 2016$ & 22 & $06: 40$ & 6.1 & 476.43 & 5.4 & 9.4 & 50.0 \\
\hline $31 / 10 / 2016$ & 23 & $03: 27$ & 4.3 & 58.72 & 2.6 & 11.0 & 44.0 \\
\hline $31 / 10 / 2016$ & 24 & 07:05 & 4.4 & 82.16 & 7.3 & 20.0 & 43.1 \\
\hline $01 / 11 / 2016$ & 25 & $07: 56$ & 4.7 & 18.14 & 23.5 & 9.9 & 73.5 \\
\hline $02 / 11 / 2016$ & 26 & $19: 37$ & 4.0 & 4.47 & 10.9 & 10.0 & 56.5 \\
\hline 03/11/2016 & 27 & $00: 35$ & 4.7 & 36.45 & 26.7 & 8.0 & 35.3 \\
\hline
\end{tabular}

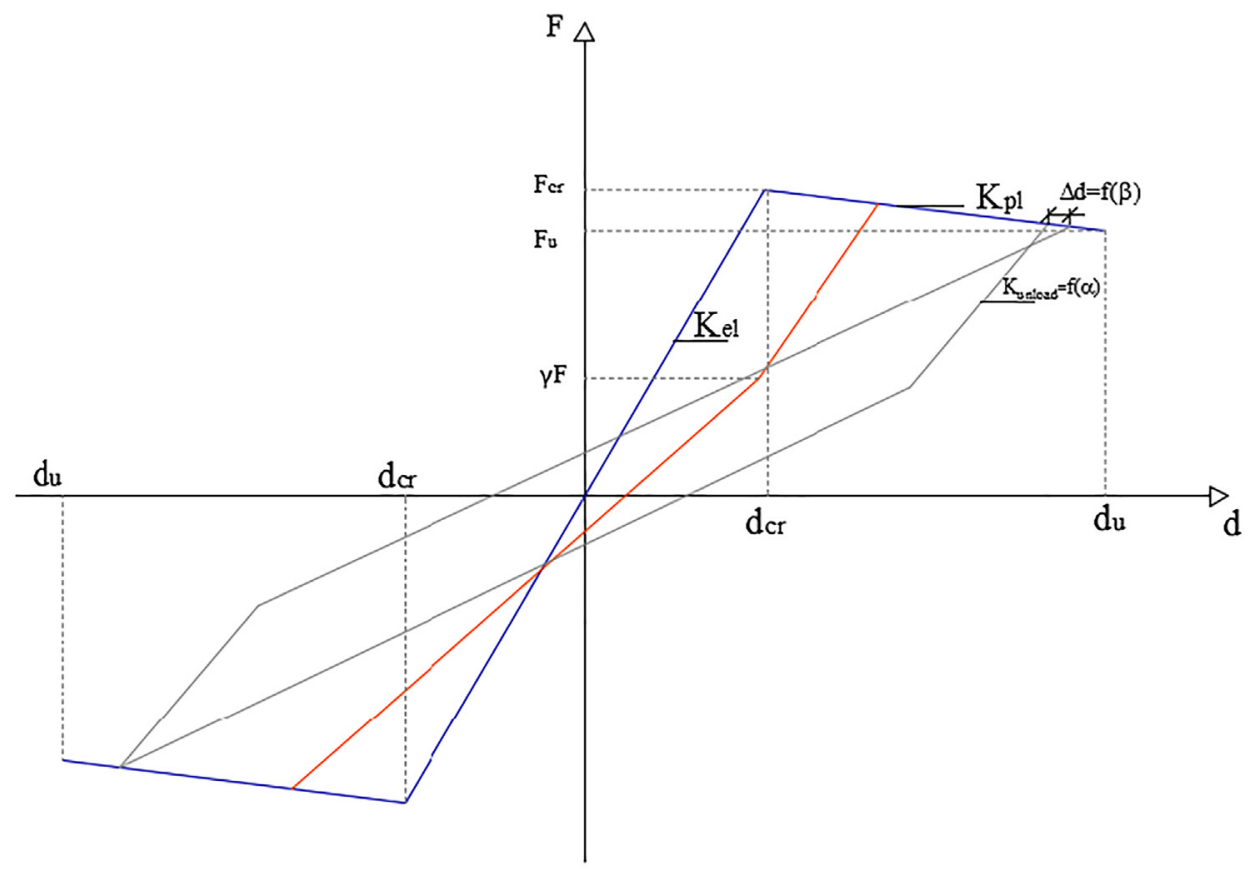

Fig. 2. Hysteresis law adopted for the SDOF system.

hand, the simplifying approach given by N2 method in European codes [8] undoubtfully allows for that.

In the last part of this work, with the aim to investigate the damage evolution under repeated events, a SDOF system will be subjected to the Central Italy seismic sequence. The Park \& Ang $[9,10]$ index will be used to quantify the damage evolution.

\section{Selection of seismic sequences}

In the paper, only records from real earthquakes are chosen, since, as previously outlined in [3], artificially generated records have too many drawbacks. Such selection is operated mainly on the seismic sequences composed by single events with different PGA, duration and frequency content.

Several record databases have been used, such as the Italian database ITACA [11], the Japanese repository NIED [12] and the international collection COSMOS [13]. Ten natural sequences, already employed in [14] and listed in Table 1, have been adopted.

To this ones, the recent sequence of Central Italy has been added. Such records have been selected from the database ESM [15] and 


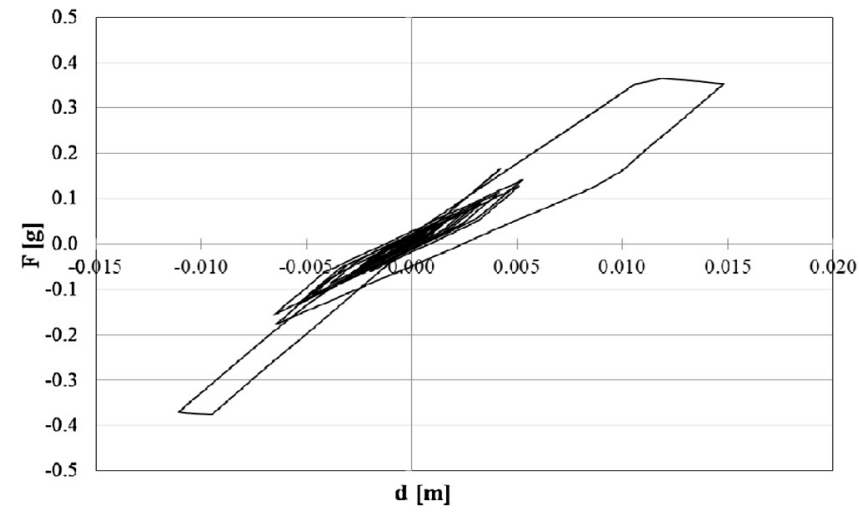

(a)

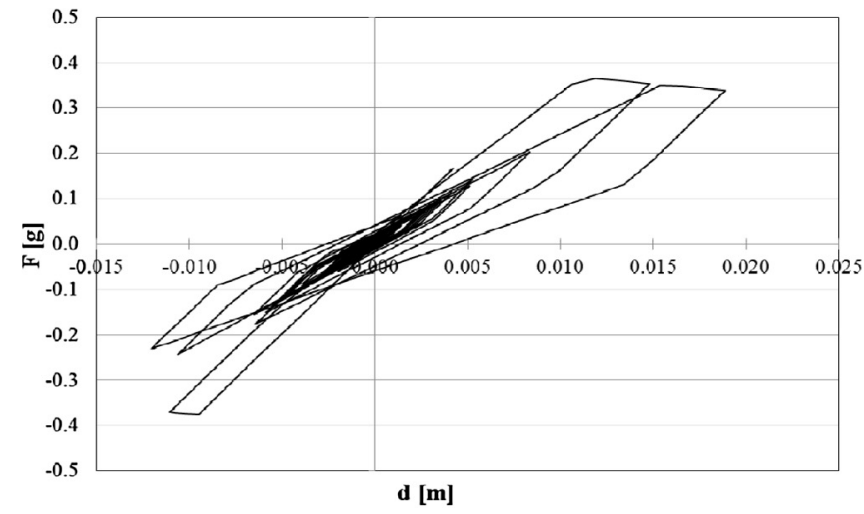

(b)

Fig. 3. Force-displacement cycles for a SDOF with $T=1 \mathrm{~s}$ subjected to the Mendocino Cape sequence after the mainshock (a) and at the end of the sequence (b).

(a)

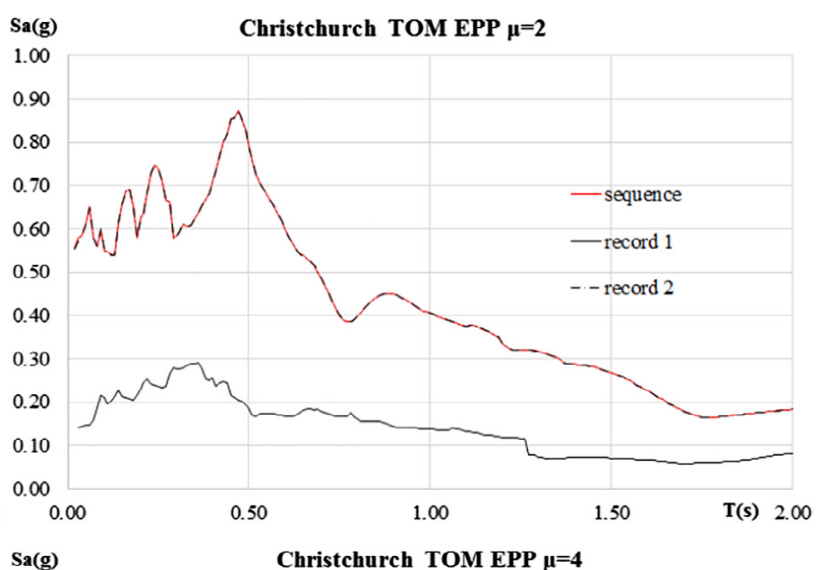

(c)

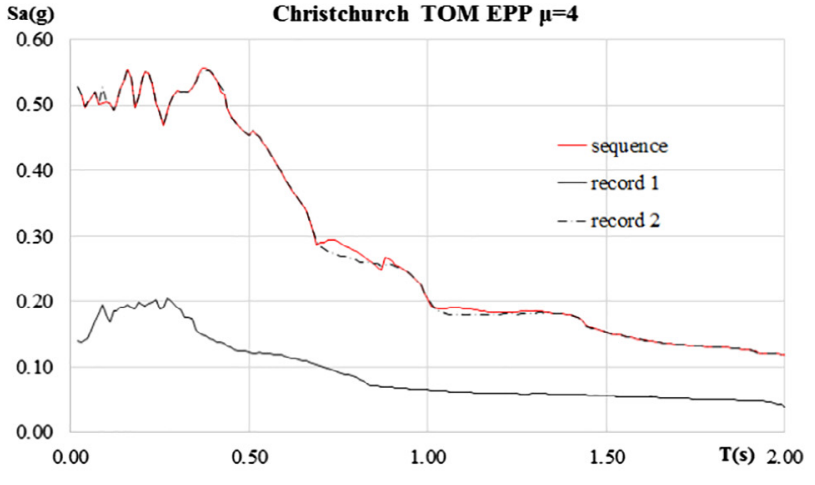

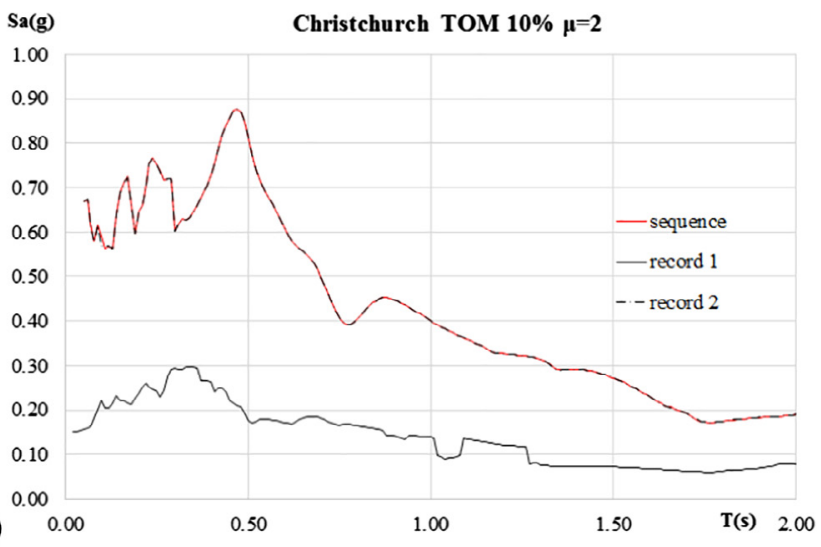

(b)

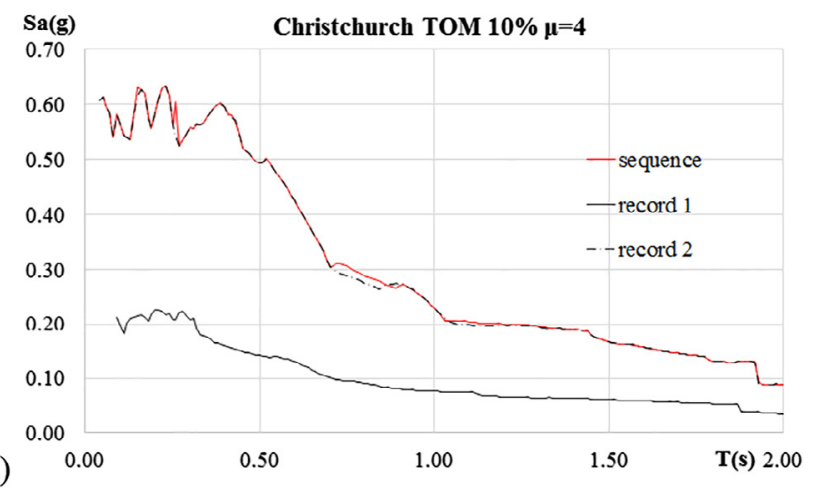

Fig. 4. Inelastic spectra for Christchurch sequence for $\mu=2$ (a, b) and 4 (c, d) and with TOM EPP (a, c) and TOM 10\% (b, d) behaviour.

include the mainshock occurred on 24th of August 2016 and more significant aftershocks until to 3rd November, for the station of Norcia. Table 2 reports the chosen events.

The composition of each sequence has been done by interposing an interval of $30 \mathrm{~s}$, which is sufficient to stop the system even for the ones with reduced damping (a damping ratio of $\xi=0.05$ has been adopted for all the records).

\section{Adopted non-linear SDOF systems}

The hysteretic law adopted to carry-out the analyses on SDOF systems has been obtained with the Tomazevic \& Lutman law [17], already used to represent the non-linear behaviour of unreinforced masonry structures in [7].

A short description of the adopted non-linear law is provided in the subsequent chapter.

\subsection{Hysteretic behaviour}

The law shown in Fig. 2 has been used; it has a bi-linear backbone curve with an elastic and a plastic branch. The slope $K_{p l}$ of the plastic branch has been varied as to obtain 3 different configurations:

1. $K_{p l}=0$ for elastic perfectly-plastic behaviour;

2. $K_{p l}=-0.05$ for a $5 \%$ softening;

3. $K_{p l}=-0.1$ for a $10 \%$ softening.

The response is collected in terms of inelastic spectrum and ductility request at a chosen strength level. Such results have been obtained through a purposely written Fortran code that performs a dynamic analysis of a SDOF system for each period, similar the one used in $[16,14]$ with other hysteresis laws.

With reference to Fig. 2, which schematically reports the main 


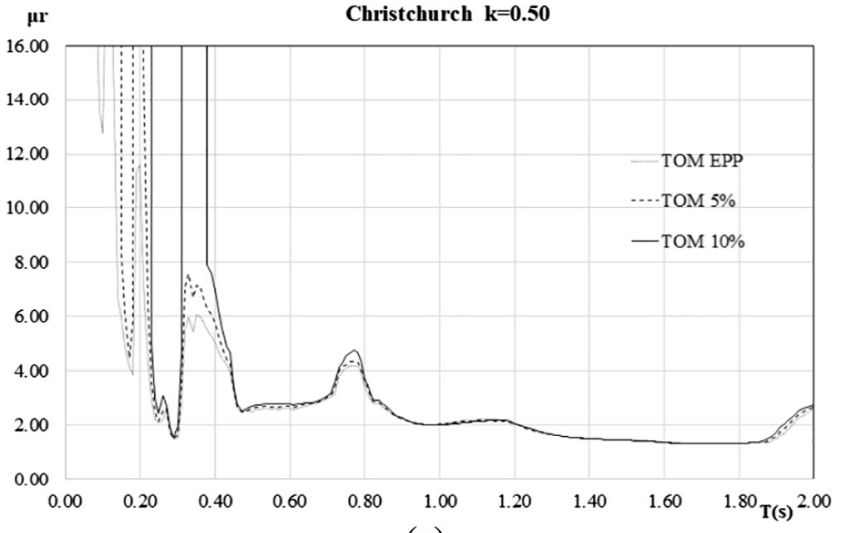

(a)

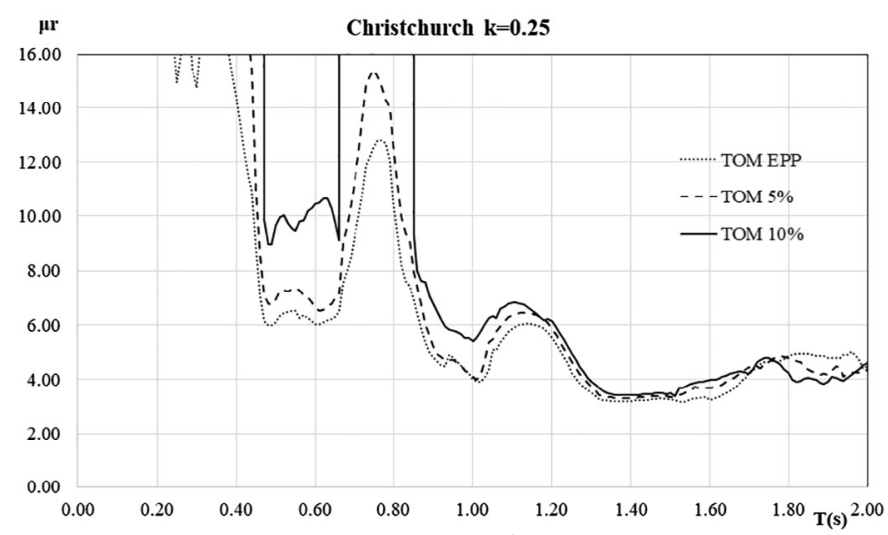

(b)

Fig. 5. Required ductility with $k=0.5$ (a) and $k=0.25$ (b) for the Christchurch sequence.
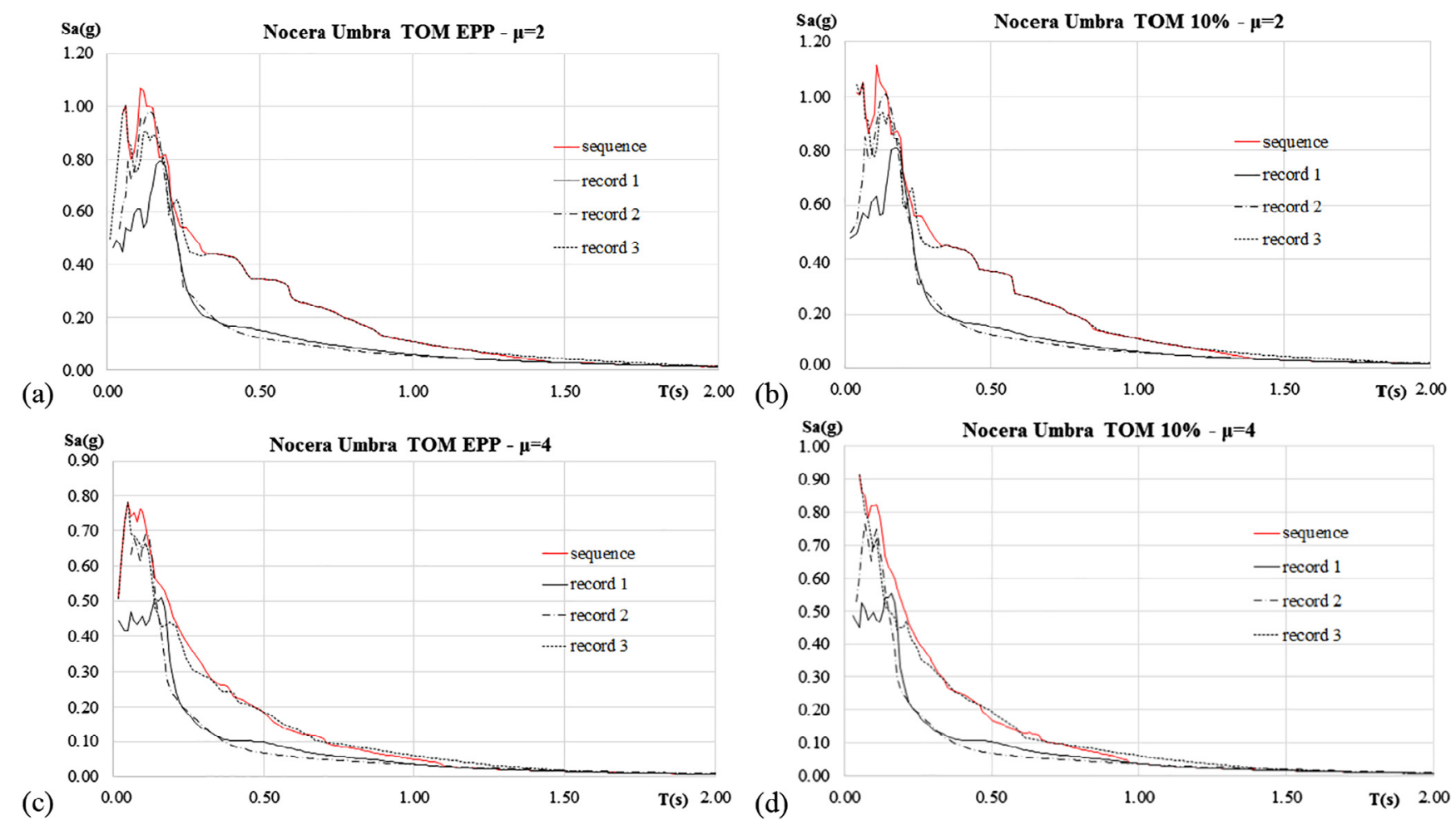

Fig. 6. Inelastic spectra for Nocera Umbra sequence for $\mu=2$ (a, b) and 4 (c, d) and with TOM EPP (a, c) and TOM 10\% (b, d) behaviour.
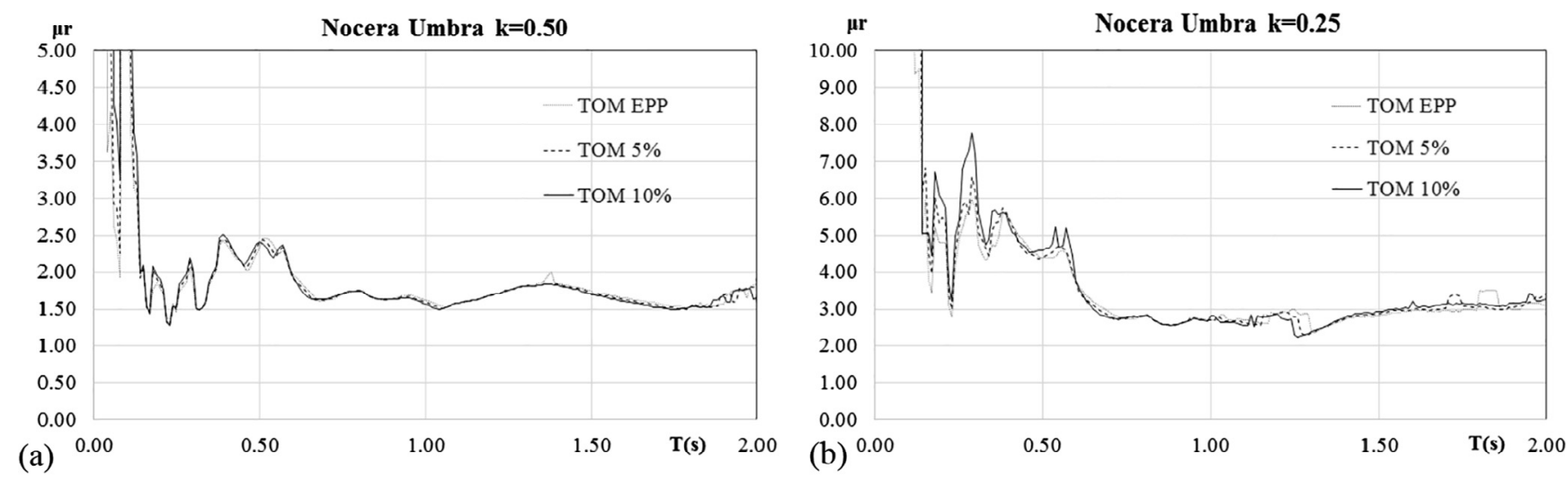

Fig. 7. Ductility request with $\mathrm{k}=0.5$ (a) and $\mathrm{k}=0.25$ (b) the Christchurch sequence. 
(a)
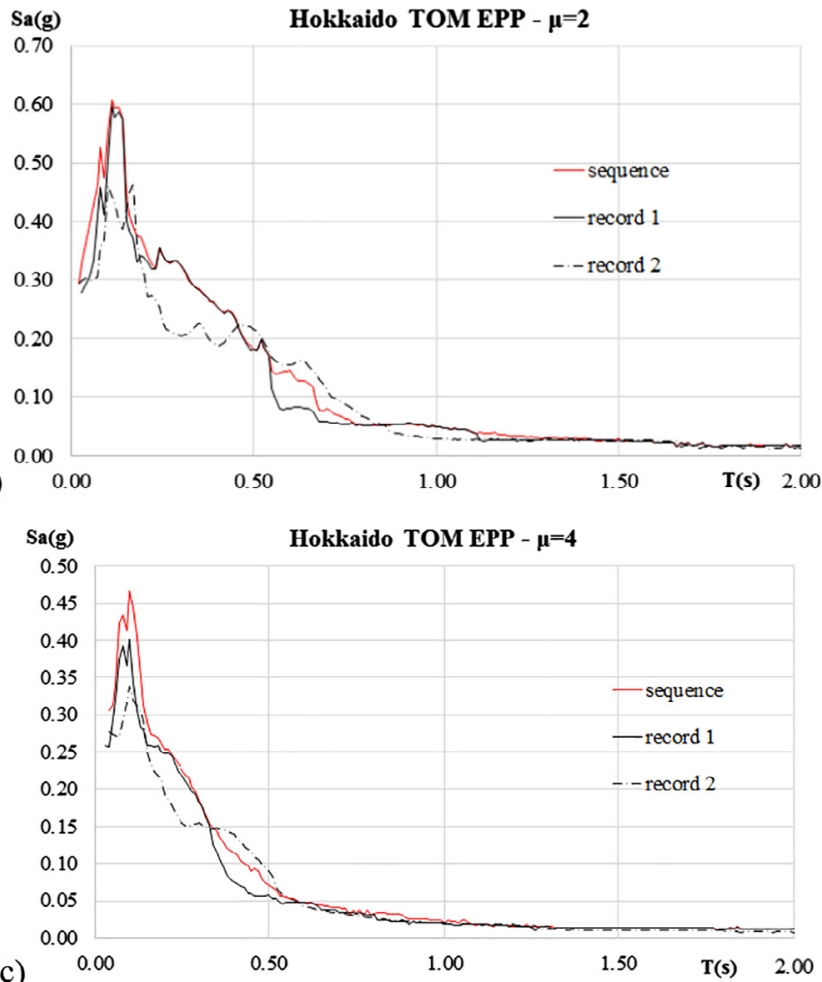

(b)

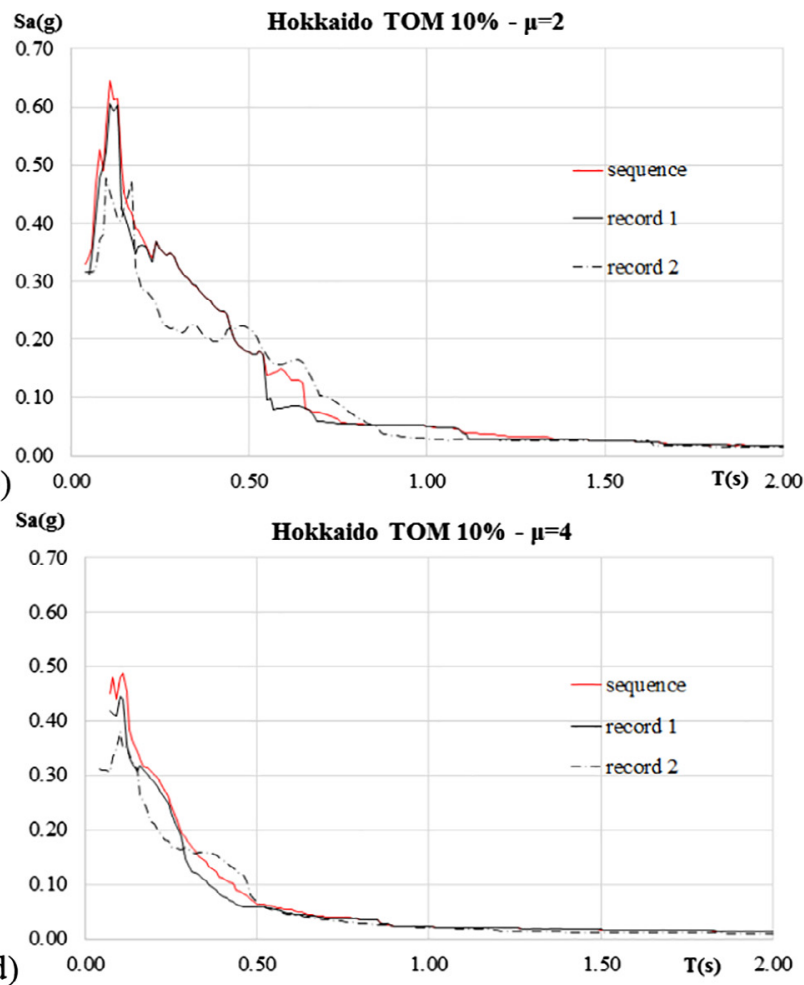

Fig. 8. Inelastic spectra for Hokkaido sequence for $\mu=2$ (a, b) and 4 (c, d) and with TOM EPP (a, c) and TOM 10\% (b, d) behaviour.
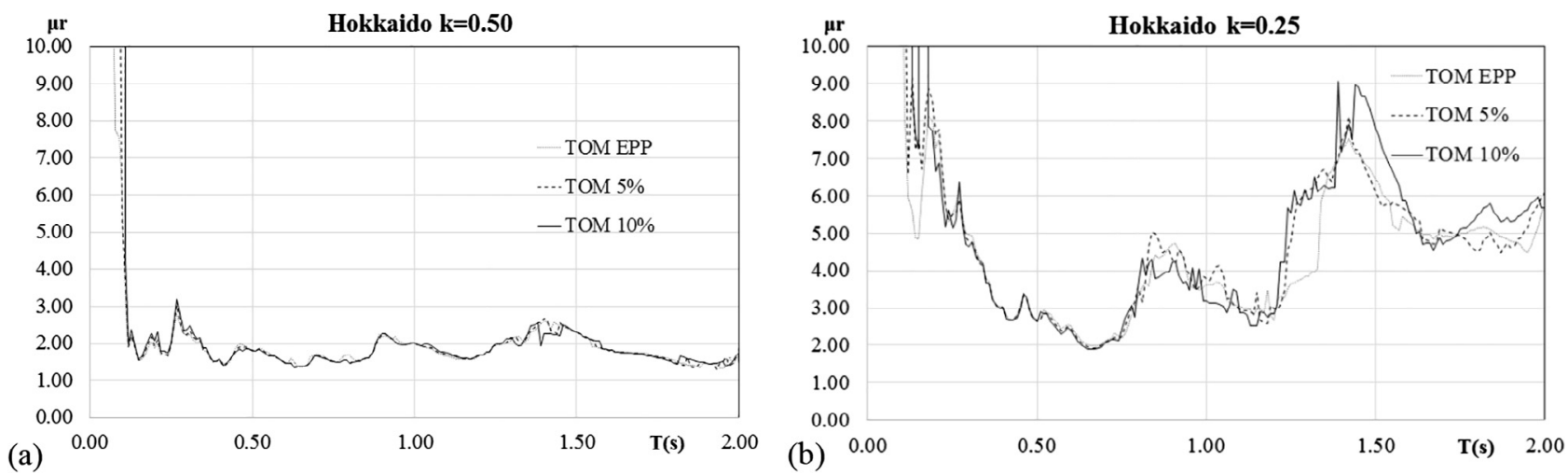

Fig. 9. Ductility request with $\mathrm{k}=0.5$ (a) and $\mathrm{k}=0.25$ (b) the Hokkaido sequence.

parameters for setting the cyclic behaviour, the unloading path is composed by 2 sequential branches: the first one leads to unloading a percentage of force equal to $\gamma$ with respect to the strength in the backbone curve, while the second branch bring the path on the negative part of the backbone.

This law implements also strength and stiffness degradations; for further information on the advanced features refer to [1]. The parameters needed to fully define the cyclic behaviour are:

1. $\mathrm{K}_{\mathrm{el}}$ elastic stiffness;

2. $\mathrm{K}_{\mathrm{pl}}$ plastic stiffness;

3. $\mathrm{F}_{\mathrm{cr}}$ force at cracking limit;

4. $\gamma$ percentage of force for the first unloading branch;

5. $\alpha$ stiffness degradation parameter;

6. $\beta$ strength degradation parameter;

7. $\mathrm{d}_{\mathrm{u}}$ ultimate displacement.

The parameters defining stiffness and strength degradation and the percentage of unloading have been taken from [17], since they were derived from an experimental campaign. Hence, the stiffness degradation parameter $\alpha$ has been set to 0.8 and the strength parameter $\beta$ to 0.06 , as already done in [7]. The percentage of unloading $\gamma$ was set to 0.6 .

\subsection{Processing of results}

Using the previously described law, the ductility levels of $\mu$ equal to 2, 3 and 4 have been investigated, obtaining for each event on every sequence the inelastic spectra at constant ductility. Such ductility values are the most representative for unreinforced masonry structures, and the upper limit of 4 has been considered since, in Italian building code $[18,19]$, the maximum behaviour factor for an existing URM building is 3.6.

This first set of results allows to investigate the ratios between the behaviour factor $q$ on the base of the ductility level by means of Eq. (1).

$R_{q}(T)=\frac{q_{\text {seq }}}{q_{\text {env }}}$ 
(a)

\section{$\mathrm{R} \mu$}
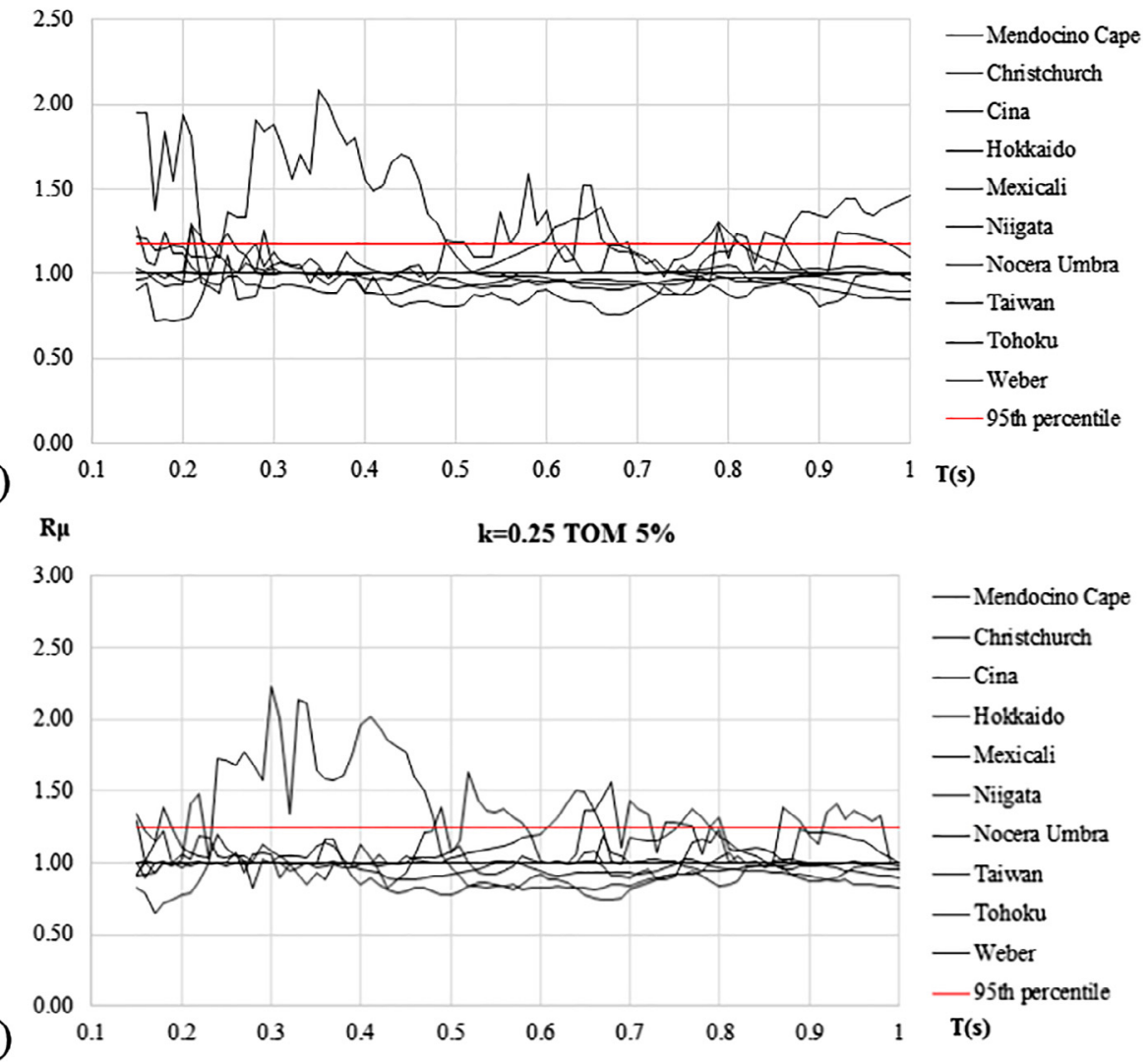

Fig. 10. Ductility ratios for all the analyses with $k=0.25$ for the TOM EPP (a) and TOM $5 \%$ (b) behaviour.

in which $q_{s e q}$ is the behaviour factor of the structure, computed for each period in $[0.01 \mathrm{~s}, 2 \mathrm{~s}]$ and every $0.01 \mathrm{~s}$ for the entire sequence, while $q_{e n v}$ is computed on the envelope of the spectra of single events composing the same sequence. To obtain $q_{e n v}$, analyses have been performed for each single event of a sequence, starting each time with an undamaged model.

The behaviour factor is estimated as the ratio between the elastic spectral acceleration $S_{a, e l}(T)$ and the inelastic one $S_{a, \text { inel }}(T)$.

In all the analyses made to obtain the inelastic spectra, the strength capacity of the SDOF system has been varied accordingly and the ductility has been kept constant. The failure of the non-linear spring has been used as control parameter, as the resulting ultimate displacement at a fixed ductility level cannot be overtaken.

With the same seismic input, an analysis with constant strength level has been performed. The strength has been chosen by reducing the strength required by the elastic spectrum of the sequence of a coefficient called $k$, as in Eq. (2).

$F_{c r}=k \cdot F_{e}=k \cdot S_{a, e l}\left(T_{i}\right)$

in which $F_{e}$ is the force required by the elastic system and $S_{a, e l}\left(T_{i}\right)$ is the acceleration of the elastic spectrum for the $T_{i}$ period.

The values of $k$ that have been employed are:

-0.25 for less resisting structures,

-0.33 for medium resisting structures,

-0.5 for high resisting structures.

Through this last kind of analysis, it is possible to evaluate the ratio between the ductility requested by the sequence and the one request made by the envelope of each single event, as in Eq. (3).
$R_{\mu}(T)=\frac{\mu_{r, s e q}}{\mu_{r, \text { env }}}$

where $\mu_{r, s e q}$ is the ductility requested by the sequence and $\mu_{r, e n v}$ is the ductility request from the envelope of the single events in the same sequence, computed with the same reduction factor $k$.

Since the reduction factors $k$ are the inverse of the ductility levels investigated, as already shown in [14], it is important to observe that the ratio between the behaviour factors will be close to the inverse of the ratio between requested ductility levels:

$R_{q}(T) \approx \frac{1}{R_{\mu}(T)}$

In this second kind of analyses, once fixed the strength reduction through the factor $\mathrm{k}$, the ductility required by the system has been evaluated. To allow such evaluation, no limit for the ultimate displacement has been set. In the softening cases, the ultimate displacement is automatically limited by the backbone curve, when the plastic branch reaches zero-force. Since in this case the non-linear spring reaches failure, this could lead to out-of-scale ductility requests, as will be shown in Fig. 5 .

\subsection{Damage estimation}

To estimate the structural damage cumulated during the analysis, and in general, after a single event in a seismic sequence, the Park \& Ang index $[9,10]$ has been used. This methodology was previously adopted in [3]. The damage index is computed as per Eq. (5):

$D I=\frac{d_{\max }-d_{c r}}{d_{u}-d_{c r}}+0.15 \frac{E_{H}}{F_{c r} d_{u}}$

where $d_{\max }$ is the maximum displacement reached, $d_{c r}$ is the 


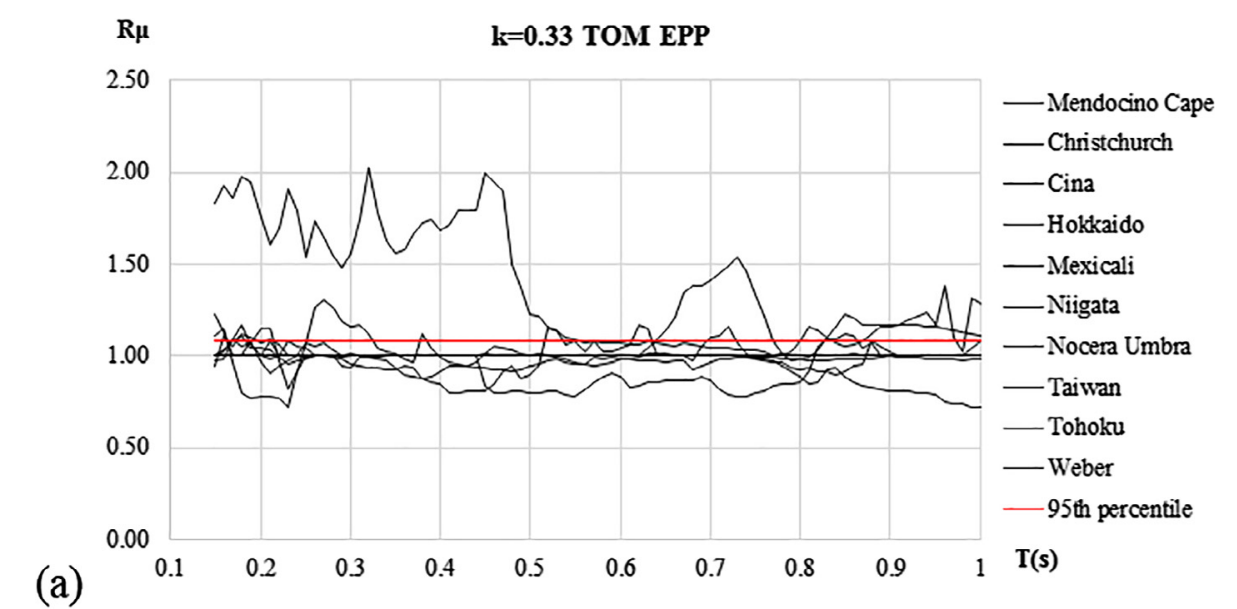

(a)
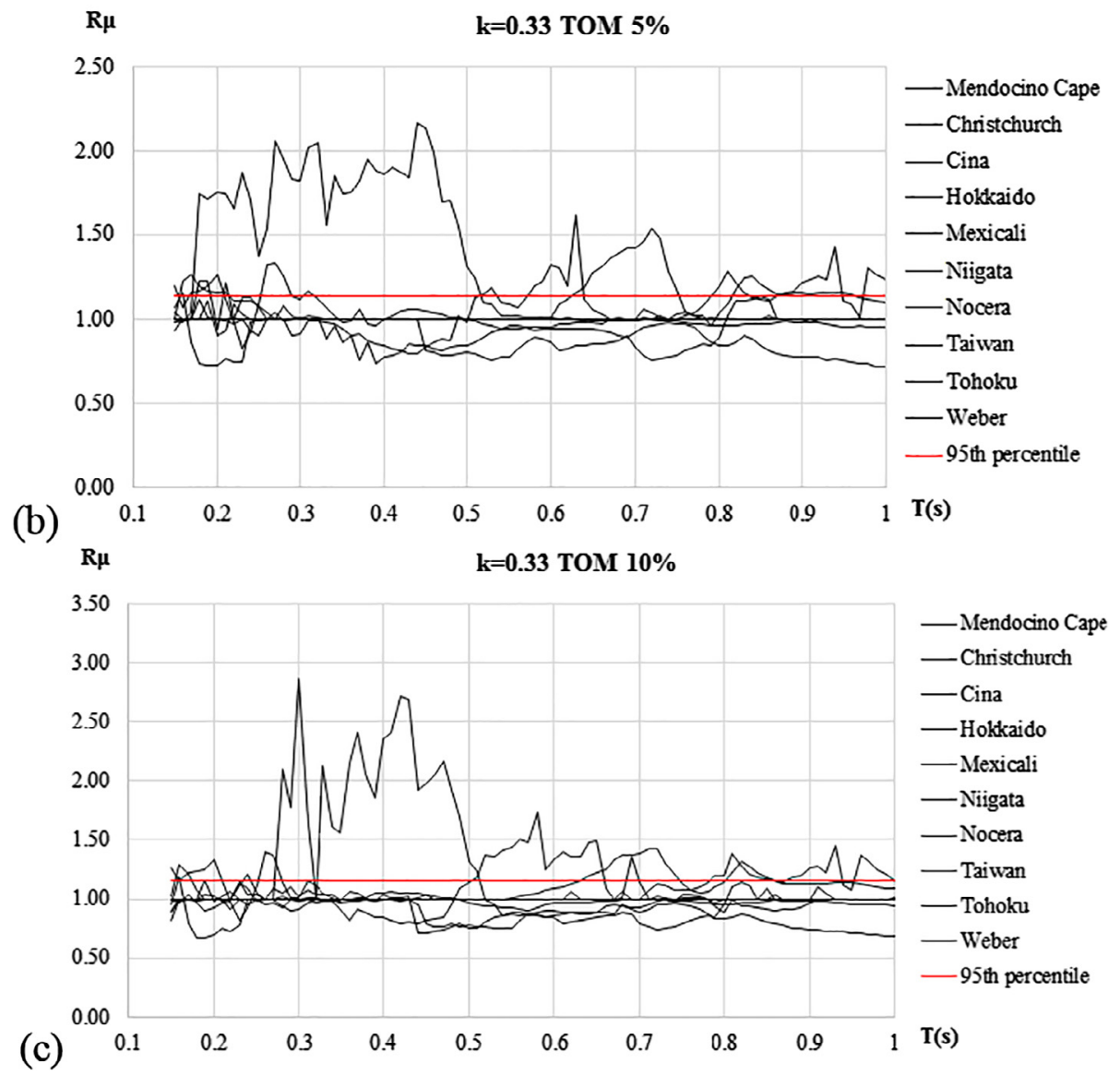

Fig. 11. Ductility ratios for all the analyses with $\mathrm{k}=0.33$ for the TOM EPP (a), TOM 5\% (b) and TOM $10 \%$ (c) behaviour.

displacement at the elastic limit, $d_{u}$ is the ultimate displacement, $E_{H}$ is the energy amount dissipated by hysteresis and $F_{c r}$ is the force at the cracking limit (see Fig. 2).

The presented index identifies the following damage levels on the base of its value:

- if $D I>0.77$, the structure is near to collapse;

- if $0.4 \leq D I<0.4$, the structure has undergone severe and non-reversible damages;

- if $D I \leq 0.4$, the building has limited damages.

The relationship in Eq. (5) has a first term depending on ductility and a second one that is a function of the dissipated energy. In such a way, both the main phenomena regulating the seismic behaviour of a masonry structure can be taken into account. With the adopted model, the Fig. 3 presents, for example, the evolution of the cyclic behaviour of a SDOF structure subjected to the Mendocino Cape sequence.

\section{Analysis results}

All the results collected from the analyses conducted with international seismic sequences are presented in the subsequent chapters. Firstly, the inelastic spectra are presented and discussed, and then ductility request is reported.

\subsection{Inelastic spectra}

In the following, results in terms of inelastic spectra are presented 
(a)

$\mathrm{R} \mu \quad \mathrm{K}=0.50$ TOM EPP

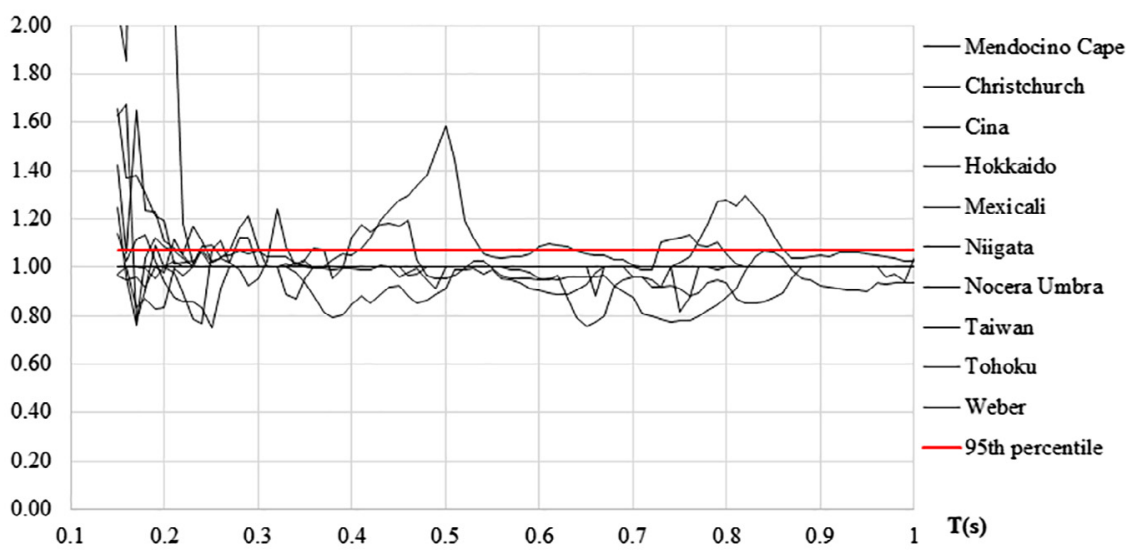

$\mathbf{R} \boldsymbol{\mu}$

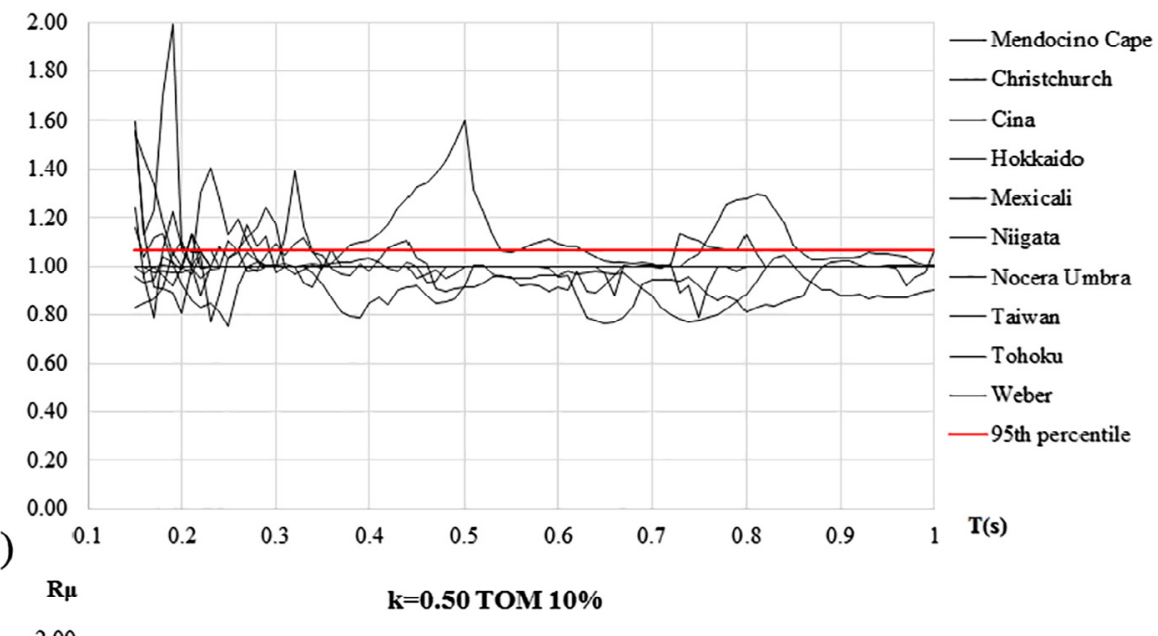

Mendocino Cape

- Christchurch

- Cina

- Hokkaido

-Mexicali

- Niigata

- Nocera Umbra

- Taiwan

- Tohoku

Weber

-95th percentile

$\mathbf{T}(\mathbf{s})$

\section{(b)}

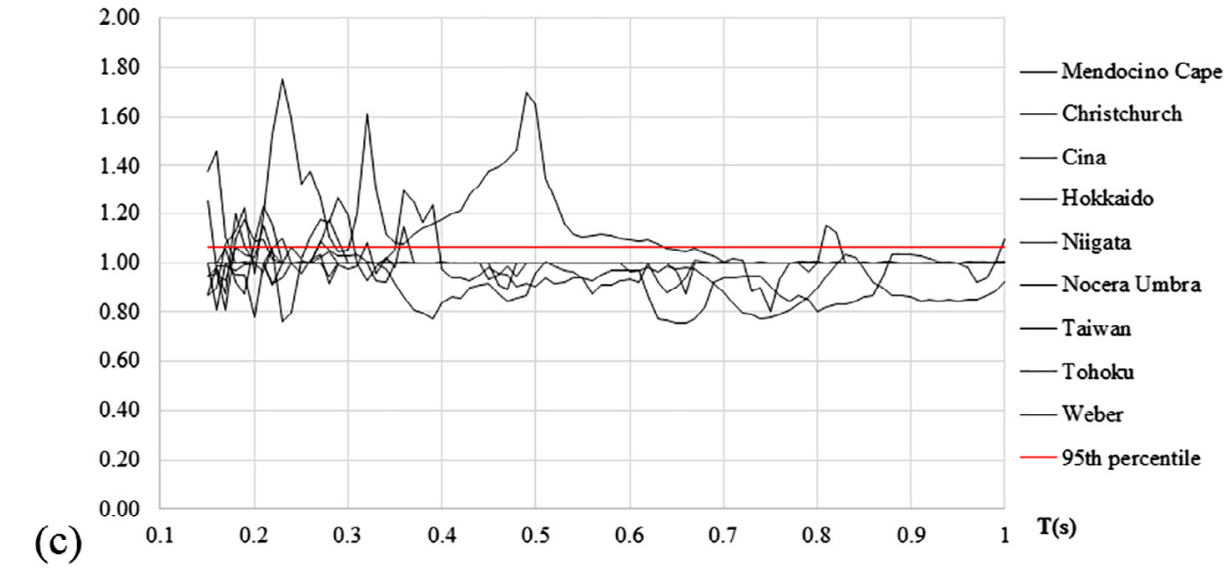

Fig. 12. Ductility ratios for all the analyses with $\mathrm{k}=0.5$ for the TOM EPP (a), TOM $5 \%$ (b) and TOM $10 \%$ (c) behaviour.

Table 3

Values of ductility ratios - 95th percentile.

\begin{tabular}{llll}
\hline Hysteresis model & \multicolumn{2}{l}{ 95th percentile } & \\
\cline { 2 - 4 } & $\mathrm{k}=0.25$ & $\mathrm{k}=0.33$ & $\mathrm{k}=0.50$ \\
\hline TOM EPP & 1.184 & 1.062 & 1.031 \\
TOM 5\% & 1.242 & 1.143 & 1.046 \\
TOM 10\% & $/$ & 1.153 & 1.110 \\
\hline
\end{tabular}

Table 4

Increase in ductility request for all the sequences.

\begin{tabular}{llll}
\hline Hysteresis model & \multicolumn{2}{l}{ Increase in ductility request } \\
\cline { 2 - 4 } & $\mathrm{k}=0.25$ & $\mathrm{k}=0.33$ & $\mathrm{k}=0.50$ \\
\hline TOM EPP & $18 \%$ & $6 \%$ & $3 \%$ \\
TOM 5\% & $24 \%$ & $14 \%$ & $5 \%$ \\
TOM $10 \%$ & $/$ & $15 \%$ & $11 \%$ \\
\hline
\end{tabular}




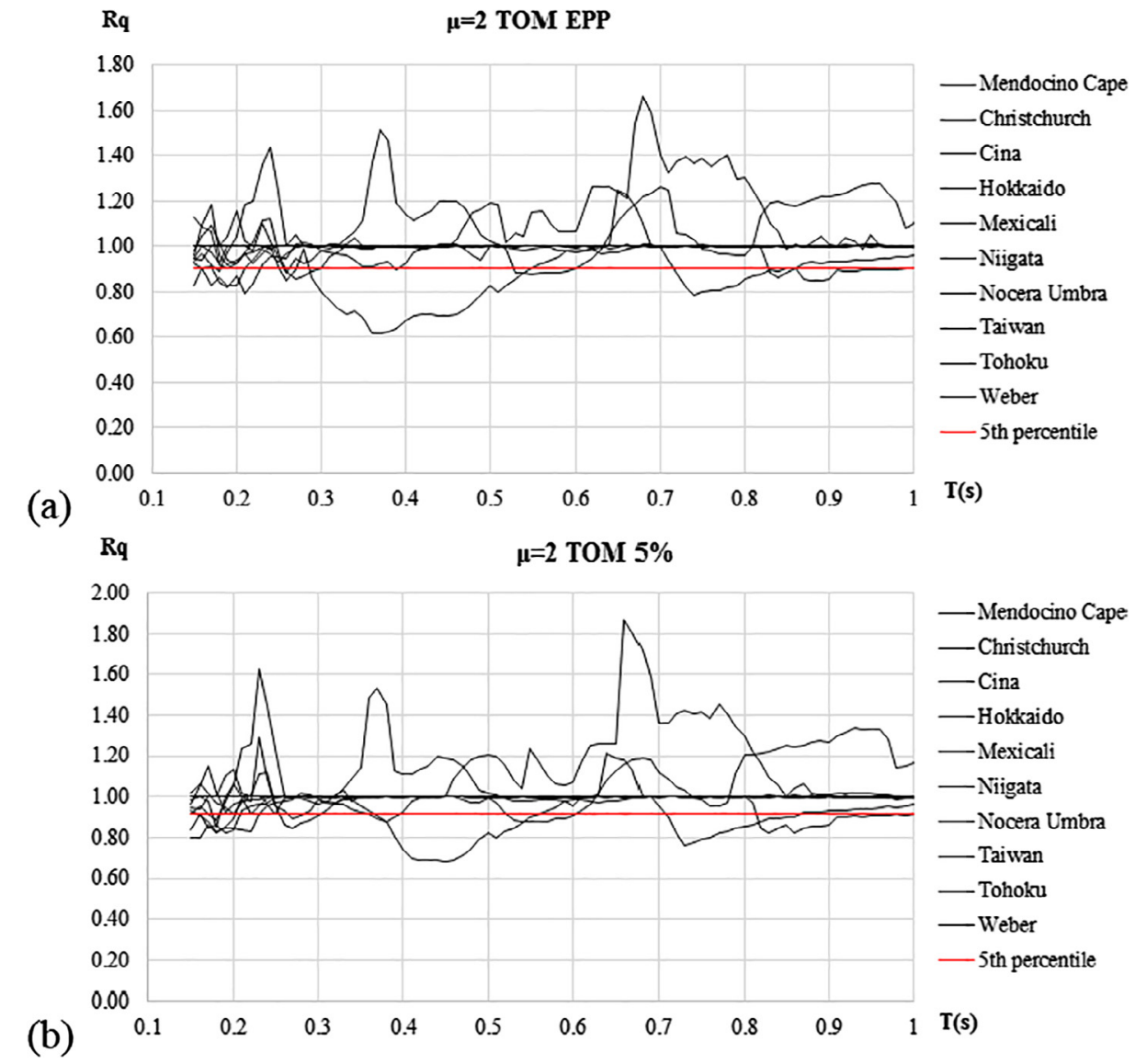

Fig. 13. Ratios between behaviour factors for all the analyses with $\mu=2$ with TOM EPP (a) and TOM 5\% (b) hysteretic behaviour.

for the sequences of Christchurch (2011), Nocera Umbra (1997) and Hokkaido (2004). Such sequences are representative of the different behaviour obtained through all the analyses. In the subsequent figures, the elastic perfectly-plastic system $\left(K_{p l}=0\right)$ has been denoted as TOM EPP, while for softening cases the writing TOM (standing for Tomazevic) is followed by the percentage of softening adopted $(5 \%$ or $10 \%)$.

Observing the Fig. 4, the strength request for the Christchurch sequence is almost coincident with the request made by the strongest event inside the sequence. This behaviour can be observed even by varying the characteristics of the hysteretic law by changing the softening. In particular, it can be noticed how, for a low ductility level, the strength request is almost completely coincident with the request of the strongest event. For higher ductility values, starting from a period of $T=0.6 \mathrm{~s}$, the requests obtained for the sequence and for the strongest event are slightly different.

For this sequence, the required ductility changing the strength parameter $k$ are reported in Fig. 5.

It is possible to observe that as the strength decreases (Fig. 5b), the required ductility increases until values that cannot be reached by the structure, in particular for shortest periods.

The sequence of Nocera Umbra shows, for a limited range of periods, a required ductility different from the one of each single event. Fig. 6 presents the inelastic spectra for EPP and 10\% softening cases for ductility levels 2 and 4, while in Fig. 7 the ductility requests of the sequence and each single event are reported for the medium-resisting buildings. As can be seen form the plot, the sequence spectrum is not always overlapped to the envelope the single events requests, for instance in the neighbourhood of $T=0.5 \mathrm{~s}$.

The sequence of Hokkaido (2004), formed by 2 events of comparable intensity, presents a ductility request which is different from the response of each single event for wide period ranges. Such effect is more evident with high ductility levels, as shown by the inelastic spectra in Fig. 8. Such behaviour is confirmed by ductility requests reported in Fig. 9.

\subsection{Requested ductility and behaviour factor ratios}

The ductility ratios, calculated as in Eq. (3), are reported in the following for all the processed sequences and for the 3 strength levels assumed. For the factor $k=0.25$, the $10 \%$ softening has not been taken into account, since it has been considered a not realistic case due to the excessive weakness of such a system.

All the results presented in the following are reported for the typical period range of URM buildings, i.e. the periods considered are between 0.15 and $1.0 \mathrm{~s}$.

A ductility ratio lesser than unity means that the ductility request made by the sequence is lesser than the one given by the envelope of each single event. For each analysed case, the 95th percentile calculated on all sequences is also reported. This has been done with the aim to represent the characteristic value which is supposed to have a limit of exceedance of $5 \%$.

The results reported in Fig. 10 are relative to the less resisting structures and show how the shape of the hysteresis cycle is not relevant in terms of ductility request, as already outlined in Amadio et al. [16]. Fig. 11 shows instead the ductility request for medium-resisting structures, Fig. 12 for the high resisting ones.

All the values of 95th percentile are listed in Table 3. From such collected values, the increase in ductility request can be extracted, as listed in Table 4.

The collected inelastic spectra allowed to calculate also the ratios between behaviour factors as in Eq. (1). The 5th percentile has been 


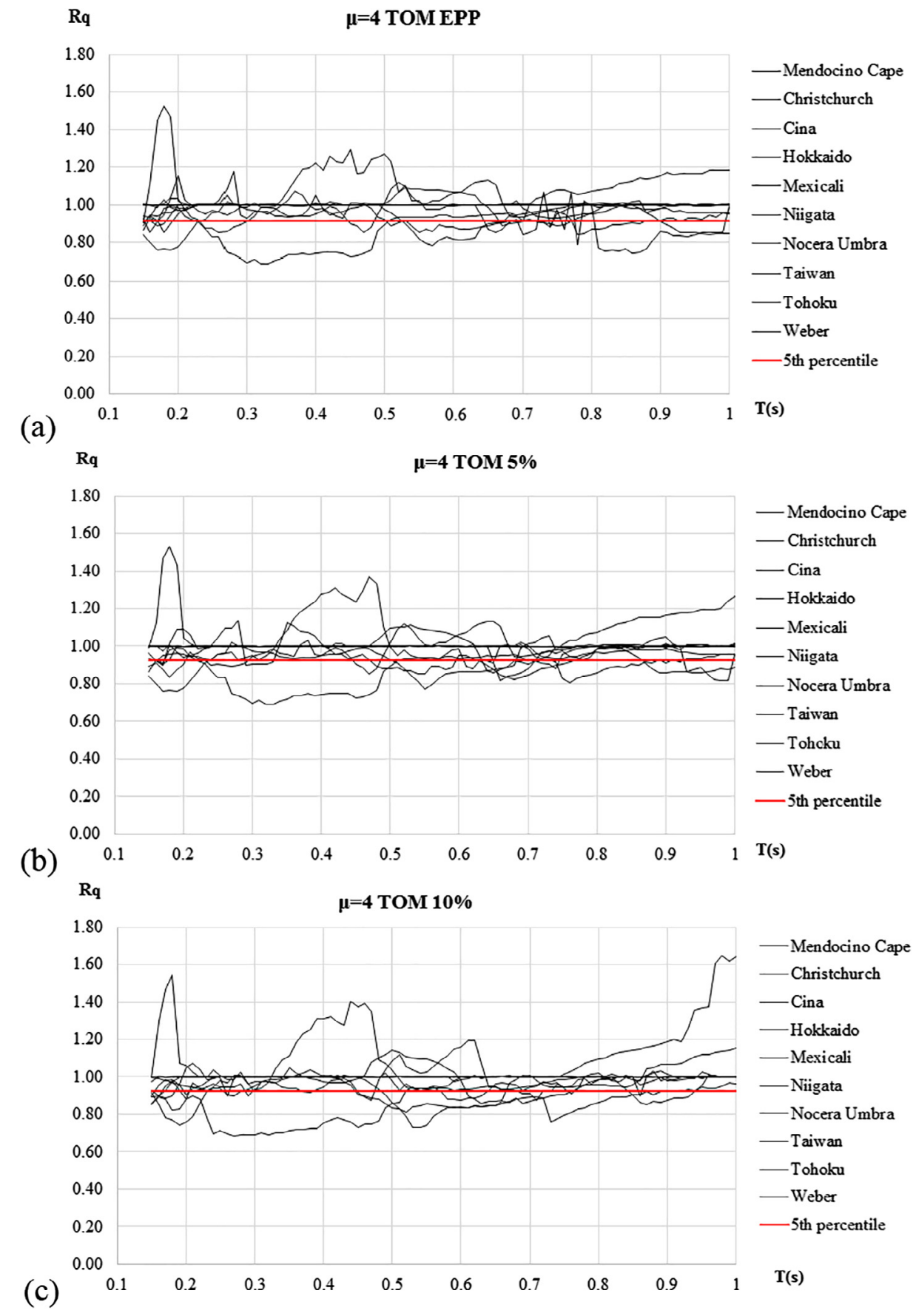

Fig. 14. Ratios between behaviour factors for all the analyses with $\mu=4$ with TOM EPP (a), TOM $5 \%$ (b) and TOM $10 \%$ (c) hysteretic behaviour.

Table 5

Behaviour factors ratios -5 th percentile.

\begin{tabular}{llll}
\hline Hysteresis model & \multicolumn{2}{l}{ 5th percentile } & \\
\cline { 2 - 4 } & $\mu=2$ & $\mu=3$ & $\mu=4$ \\
\hline TOM EPP & 0.880 & 0.881 & 0.911 \\
TOM 5\% & 0.879 & 0.882 & 0.889 \\
TOM 10\% & 0.876 & 0.897 & 0.927 \\
\hline
\end{tabular}

used for such cases, consistently to what has been done for ductility ratios. Fig. 13 shows the behaviour factor ratios for all the sequences at a constant ductility of 2, while Fig. 14 reports the ratios for ductility equal to 4 .
Table 5 reports the collected ratios on behaviour factors. It can be seen how the resulting reduction for behaviour factor is similar to the inverse of the increase in ductility demand in Table 3 . In this way, the same values proposed in Table 4 can be used to reduce the behaviour factor.

\section{Damage index evolution}

The Park and Ang $[9,10]$ damage index reported in Eq. (5) has been used to estimate the cumulative damage occurred during the seismic sequence of Central Italy 2016 (see for example Fig. 1). Such sequence is not part of the previous set, and has been purposely chosen to investigate the structural behaviour of unreinforced masonry buildings damaged or collapsed during a generic sequence [2]. The Central Italy 
DI

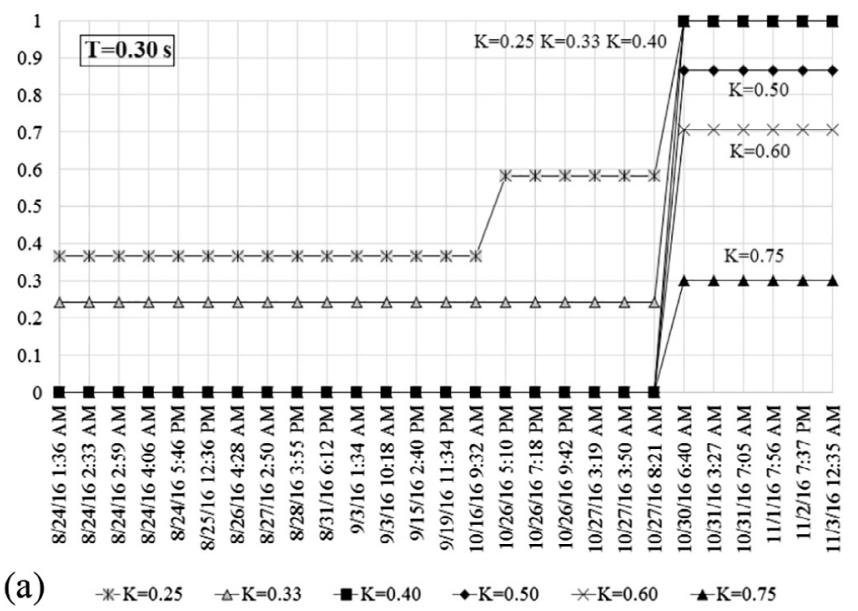

DI

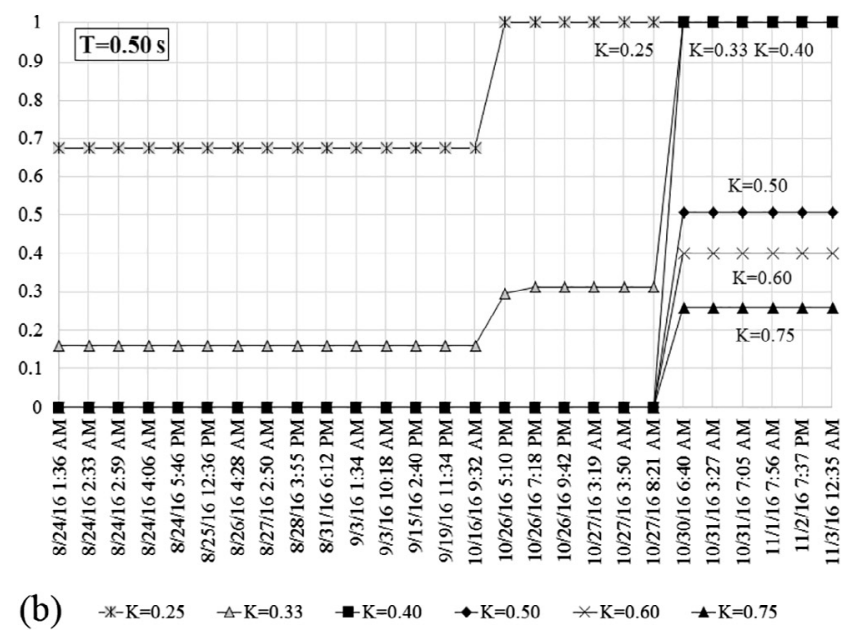

Fig. 15. Values of Damage Index (DI) for Central Italy sequence with $\mu=2$ and TOM 5\% for $T=0.3 \mathrm{~s}$ (a) and $T=0.5 \mathrm{~s}$ (b).
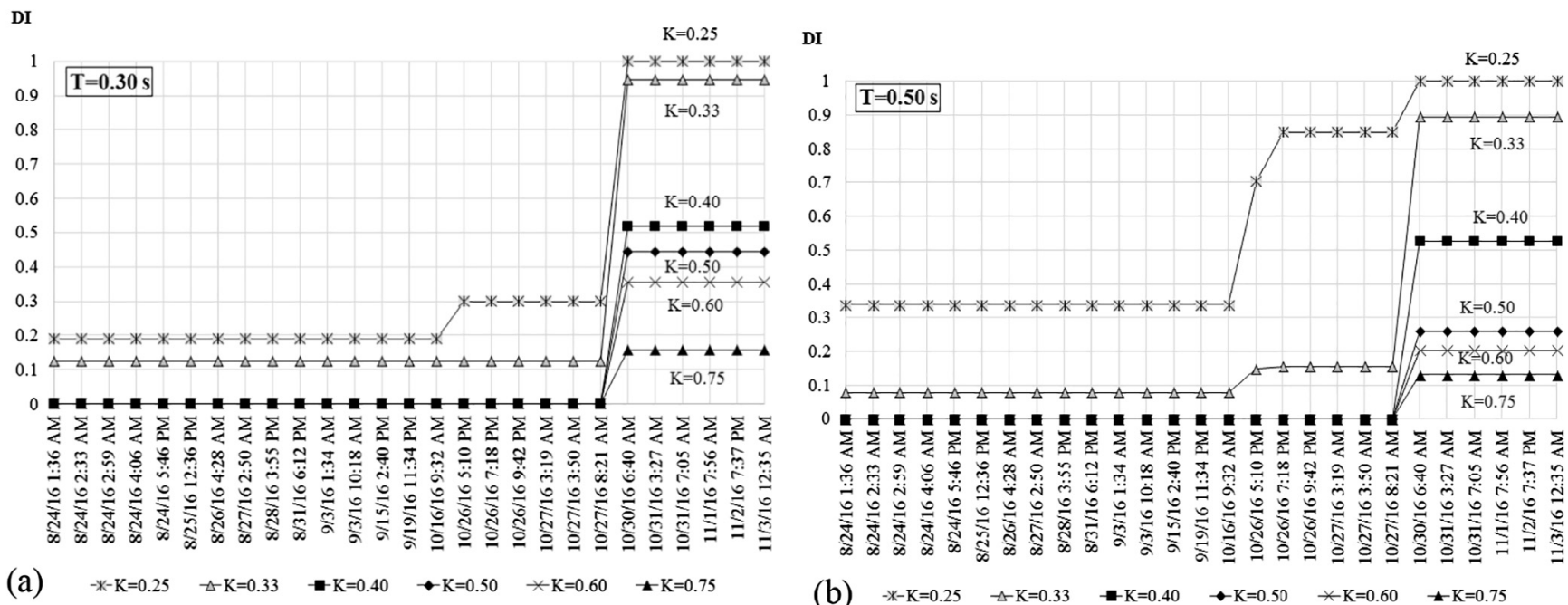

Fig. 16. Values of Damage Index (DI) for Central Italy sequence with $\mu=3$ and TOM $5 \%$ for $T=0.3 \mathrm{~s}$ (a) and $T=0.5 \mathrm{~s}$ (b).

sequence is composed by hundreds of events; only the 27 events with $M_{w} \geq 4.0$ have been considered. To better represent such URM structures, mainly built with stone blocks, ductility levels 2 and 3 have been chosen, and the TOM 5\% hysteresis model was adopted. The same SDOF model has been employed, and, with the aim to investigate the effects of strength variations, more values of $k$ parameter have been used (from 0.25 to 0.75 ).

The collected results are shown in terms of time evolution (eventby-event) of the Damage Index (DI). Fig. 15 shows the results for structures having a fundamental period $T$ of 0.3 and $0.5 \mathrm{~s}$ and ductility equal to 2, while Fig. 16 reports the results of the same analyses for a ductility equal to 3 . Observing results plotted in these figures, it is evident as only the masonry structures having from moderately to high strength do not have damages with the mainshock of August 24th and survived the entire sequence, avoiding the collapse.

The less resisting structures underwent a considerable damage with the mainshock, and reached the collapse $(D I=1)$ with the October 30 th event, or even earlier in some cases (i.e. $k=0.25$ ).

It can be observed how structures having a ductility $\mu=2$ and $k=0.6$, which is equivalent to a behaviour factor $q=1 / k=1.67$, can survive the sequence, while the ones with $k=0.5$ cannot. For a ductility $\mu=3$, the same behaviour is observed for $k=0.4$, which is equivalent to a behaviour factor $q=2.5$. Such values are very close the ones suggested in the previous section of this work.

\section{Conclusions}

In this work, the cyclic behaviour of unreinforced masonry structures subjected to a seismic sequence is investigated. Ten international sequences have been used as input for a non-linear SDOF model, having a properly defined hysteretic behaviour. Inelastic spectra and the required ductility have been collected through non-linear dynamic analyses.

Such data were processed to obtain a correction of the behaviour factors commonly used in elastic force-based design. In fact, the current design codes do not take into account the reduction of behaviour factor due to repeated seismic events that could follow up the mainshock. From a resilience-based standpoint in practical design [3], it is then important to consider reduced behaviour factors in order to allow the structure to survive the entire earthquake swarm.

The presented results show a significant behaviour factor reduction due to a sequence for URM structures (up to $24 \%$ for the less resisting structures). Since the structural behaviour is mainly governed by ductility, in this way, the behaviour factor reduction can be seen as the inverse of the required ductility increment. The proposed corrections on behaviour factors and the conclusions drawn are referred in particular 
to the evaluation of the seismic vulnerability of existing masonry building, with the final aim to allow professional designers to increase the structural strength or the overall ductility.

The analysis carried-out with the Central Italy sequence occurred on 2016 evidenced how the Park \& Ang index can highlight significantly the damage evolution in a URM structures subjected to repeated seismic events.

\section{References}

[1] ReLUIS-INGV Workgroup. Preliminary study of Rieti earthquake ground motion records V4; 2016. Available at < http://www.reluis.it > .

[2] Valensise G, Tarabusi G, Guidoboni E, Ferrari G. The forgotten vulnerability: a geology-and history-based approach for ranking the seismic risk of earthquakeprone communities of the Italian Apennines. Int J Disaster Risk Reduct 2017;25:289-300.

[3] Amadio C, Fragiacomo M, Rajgelj S. The effects of repeated earthquake ground motions on the non-linear response of SDOF systems. Earthquake Eng Struct Dyn 2003;32(2):291-308.

[4] Hatzigeorgiou GD, Beskos DE. Inelastic displacement ratios for SDOF structures subjected to repeated earthquakes. Eng Struct 2009;31:2744-55.

[5] Bruneau M, Reinhorn A. Overview of the resilience concept. In: Proceedings of the 8th U.S. National Conference on Earthquake Engineering, 2040, April 18-22, 2006, San Francisco, California, USA; 2006.

[6] Italian Government, Dipartimento di Protezione Civile. Terremoto Centro Italia; 2017. DPC Internet site: < http://www.protezionecivile.gov.it/jcms/it/terremoto_ centro_italia_2016.wp > .

[7] Rinaldin G, Amadio C, Macorini L. A macro-model with nonlinear springs for seismic analysis of URM buildings. Earthquake Eng Struct Dyn 2016;45(14):2261-81. http://dx.doi.org/10.1002/eqe.2759.
[8] CEN. Eurocode 8: Design of structures for earthquake resistance-Part 1: General rules, seismic actions and rules for buildings. Brussels: European Committee for Standardization; 2005.

[9] Park YJ, Ang AHS. Mechanistic seismic damage model for reinforced concrete. J Struct Eng (ASCE) 1985;111(4):722-39.

[10] Park YJ, Ang AHS, Wen YK. Seismic damage analysis of reinforced concrete buildings. J Struct Eng 1985;111(4):740-57.

[11] Luzi L, Hailemikael S, Bindi D, Pacor F, Mele F, Sabetta F. ITACA (ITalian ACcelerometric Archive): a web portal for the dissemination of Italian strong-motion data. Seismol Res Lett 2008;79(5):716-22. http://dx.doi.org/10.1785/gssrl.79. 5.716.

[12] Fujiwara H, Aoi S, Kunugi T, Adachi S, et al. Strong-motion Observation Networks of NIED: K-NET and KiK-net. Cosmos Report; 2004.

[13] Archuleta RJ, Jamison S, Melinda S. The COSMOS Virtual Data Center: a web portal for strong motion data dissemination. Seismol Res Lett 2006;77(6):651-8.

[14] Rinaldin G, Amadio C, Fragiacomo M. Effects of seismic sequences on structures with hysteretic or damped dissipative behaviour. Soil Dyn Earthquake Eng 2017;97:205-15. http://dx.doi.org/10.1016/j.soildyn.2017.03.023.

[15] Luzi L, Puglia R, Russo E \& ORFEUS WG5. Engineering Strong Motion Database, version 1.0. Istituto Nazionale di Geofisica e Vulcanologia, Observatories \& Research Facilities for European Seismology; 2016. http://dx.doi.org/10.13127/ ESM.

[16] Amadio C, Rinaldin G, Fragiacomo G. Investigation on the accuracy of the N2 method and the equivalent linearization procedure for different hysteretic models. Soil Dyn Earthquake Eng 2016;83:69-80. http://dx.doi.org/10.1016/j.soildyn. 2016.01.005.

[17] Tomazevic M, Lutman M. Seismic behavior of masonry walls - modeling of hysteretic rules. J Struct Eng 1996:1048-54.

[18] Min. Infrastrutture e Trasporti. D.M. 14 Gennaio 2008 - Norme tecniche per le costruzioni, Italian building code, in Italian; 2008.

[19] Min. Infrastrutture e Trasporti. Circ. n.617 del 02 Febbraio 2009 - Istruzioni per l'applicazione delle Norme tecniche per le costruzioni, commentary on the Italian building code, in Italian; 2009. 